\title{
Cost-benefit analysis
}

A practical guide 
Downloaded by [] on [26/04/23]. Copyright @ ICE Publishing, all rights reserved. 


\title{
Cost-benefit analysis
}

\section{A practical guide}

\section{Second edition}

\author{
Michael Snell
}

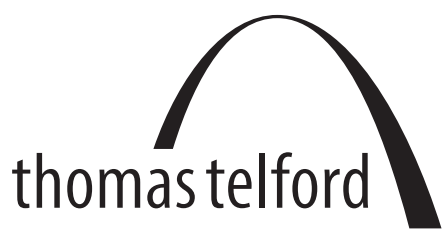


Published by Thomas Telford Limited, 40 Marsh Wall, London E14 9TP.

www.thomastelford.com

Distributors for Thomas Telford books are

USA: Publishers Storage and Shipping Corp., 46 Development Road, Fitchburg, MA 01420

Australia: DA Books and Journals, 648 Whitehorse Road, Mitcham 3132, Victoria

First published 1997

Also available from Thomas Telford Limited

Planning Major Projects. R.J. Allport. ISBN 978-0-7277-4110-3

Asset Management. C. Lloyd (ed.). ISBN 978-0-7277-3653-6

Art and Practice of Managing Projects. A. Hamilton. ISBN 978-0-7277-3456-3

www.icevirtuallibrary.com

A catalogue record for this book is available from the British Library

ISBN: 978-0-7277-4134-9

Copyright Michael Snell (C) 2011

All rights, including translation, reserved. Except as permitted by the Copyright, Designs and Patents Act 1988, no part of this publication may be reproduced, stored in a retrieval system or transmitted in any form or by any means, electronic, mechanical, photocopying or otherwise, without the prior written permission of the Publisher, Thomas Telford Limited, 40 Marsh Wall, London E14 9TP.

This book is published on the understanding that the author is solely responsible for the statements made and opinions expressed in it and that its publication does not necessarily imply that such statements and/or opinions are or reflect the views or opinions of the publishers. Whilst every effort has been made to ensure that the statements made and the opinions expressed in this publication provide a safe and accurate guide, no liability or responsibility can be accepted in this respect by the author or publishers.

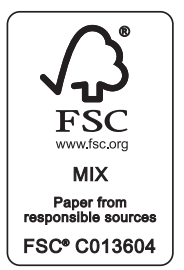

Typeset by Academic + Technical, Bristol

Index created by Indexing Specialists (UK) Ltd, Hove, East Sussex

Printed and bound in Great Britain by CPI Antony Rowe Limited, Chippenham and Eastbourne 


\section{Contents}

Preface to the first edition $\quad$ ix

Preface to the second edition $\quad$ xi

Introduction xiii

1 Basic principles of cost-benefit analysis 1

1.1 A set of tools for guiding decisions 1

1.2 A common unit of measurement 2

1.3 Types of cost-benefit analysis 3

1.4 The decision-making context 6

1.5 Value judgements 7

1.6 Analysts, decision-makers and transparency 7

1.7 Risk, uncertainty and pragmatism 8

1.8 Stages of the planning-design-implementation process 8

1.9 The main stages of a cost-benefit analysis 10

Notes 11

2 Quantifying and valuing the costs and benefits 13

2.1 Costs and benefits in the with-project and

without-project situations 13

2.2 Costs and benefits that are sometimes not counted 16

2.3 Defining the common unit of measurement 24

2.4 Shadow pricing: practical application 26

2.5 Rationale of shadow pricing 28

2.6 Valuation of particular kinds of costs and benefits 31

2.7 Double-counting 36

Notes $\quad 38$

3 Resources and time: discounting and indicators $\quad 40$

3.1 Time preference $\quad 40$

3.2 Discounting 42

3.3 Indicators and their calculation 46 
Cost-benefit analysis - A practical guide

3.4 Length of analysis period 52

3.5 Inflation, depreciation and loans 54

3.6 Choice of indicator for particular purposes $\quad 57$

3.7 Sensitivity tests 61

3.8 Terminology and reporting 66

3.9 The appropriate discount rate 68 $\begin{array}{ll}\text { Notes } & 75\end{array}$

4 Application to particular fields $\quad 78$

$\begin{array}{lll}4.1 & \text { General } & 78\end{array}$

4.2 Agriculture 82

4.3 Health projects and programmes 90

4.4 Water supply, sanitation, public health 94

4.5 Education 96

4.6 Flood and coastal protection, environment, recreation 98

4.7 Transport 111

4.8 Energy 115

4.9 Urban and regional planning 117

$\begin{array}{ll}\text { Notes } & 117\end{array}$

5 Reporting and presentation $\quad 120$

5.1 Definition of the project 122

5.2 Methodology and assumptions $\quad 123$

5.3 Statement of price basis 123

5.4 Probabilistic aspects of benefit estimates 124

5.5 Treatment of sensitive demand forecasts 125

5.6 Optimisation of timing 125

$\begin{array}{lll}5.7 & \text { Financial analysis } & 127\end{array}$

5.8 Size optimisation and choice of indicator 128

5.9 Graphical presentation of sensitivity test results $\quad 129$

5.10 Sensitivity tests in text 131

5.11 Summary 133

Note 133

6 Checklist 134

$\begin{array}{ll}\text { APPENDICES } & 139\end{array}$

A Uncertainty, probability and risk 141

A.1 Basic concepts 141

A.2 Attitudes to uncertainty 149

A.3 Ways of handling uncertainty in CBA 153

vi 
A.4 Summary and recommendations $\quad 159$

A.5 Further reading and information sources 159 Notes 160

B The domestic pricing and foreign exchange numéraires 163

B.1 Introduction 163

B.2 Traded and non-traded goods 164

B.3 The domestic pricing system 164

B.4 The foreign exchange system 165

B.5 Comparison of the two systems 166

B.6 Choice of system 167

B.7 Further reading and information sources 169 Notes 170

C Ways of estimating economic prices 172

C.1 Introduction and underlying principles 172

C.2 Market prices with adjustments 175

C.3 Opportunity cost approaches 178

C.4 Stated preferences; contingent valuation 182

C.5 Proxy markets and other revealed-preference approaches 184

C.6 Shadow pricing as an instrument of policy 188

C.7 Choice of valuation method 188

C.8 Benefit transfer 189

C.9 Further reading and information sources 190 Notes 191

D Distribution of costs and benefits between people 195

D.1 General distribution adjustments 195

D.2 Income weighting 196

D.3 Use of distributional weighting 198

Notes 198

E Choice of discount rate 200

E.1 Introduction 200

E.2 Individual and social time preference 201

E.3 Opportunity cost of capital 202

E.4 Capital rationing device 203

E.5 Risk and the discount rate 204

E.6 Synthesis 205

E.7 Further reading and information sources 207

Notes 209 
F Multicriterion decision analysis

F.1 Introduction 212

F.2 Basic concepts and techniques 214

F.3 Non-numerical methods 220

F.4 A simple numerical method 221

F.5 Other methods 225

F.6 Uncertainty and incomplete information 229

F.7 Further reading and information sources 229

Notes 230

G The effects method 232

Notes 233

H Model answers to readers' worked examples 235

I Worked example 241

I.1 Introduction 241

I.2 The project 241

I.3 Economic prices 243

I.4 Farm level financial analysis 245

I.5 Economic benefits 246

I.6 Economic costs 249

I.7 Cost-benefit indicators 250

I.8 Sensitivity tests 251

I.9 Conclusion 253

I.10 Postscript 254

J Discounting tables 256

$\begin{array}{ll}\text { K Bibliography } & 267\end{array}$

$\begin{array}{ll}\text { Glossary/index } & 281\end{array}$ 


\section{Preface to the first edition}

This book aims to meet the needs of engineers, planners, environmentalists and other professionals who occasionally use cost-benefit analysis (CBA) or related project appraisal techniques, or who prepare inputs for such analyses. It will also be useful to people who take decisions that are partly guided by CBA - officials, politicians and representatives of particular groups affected by a project or a plan. The book will help those who lead multidisciplinary teams or edit multifaceted documents in which CBA is one aspect among many. It can also serve as a source book for economists needing to deepen or update their knowledge of CBA.

The book is intended to be used in two complementary ways:

- firstly, as a learning tool whereby the reader can, starting with basic arithmetic but no training in economics, understand the rationale of CBA and learn to carry out many of the operations

- secondly, as a reference book, which a planner, engineer, economist or other professional, who has already learned the techniques and is applying them, can turn to for a reminder of basic principles or for details on a particular sort of analysis that he has not done before.

Readers will not become economists by studying this book, but they will understand more of what economists are saying. They will also be able to discuss CBA with economists and ask them the right questions, which is often necessary because economists cannot be expected to understand all the technical and planning implications of the numbers and concepts they manipulate. Some practising economists learn a great deal about other disciplines, and communication will be furthered if engineers and others can go some way to meet them. After working through this book, readers should be able to undertake some kinds of CBA unaided, especially when the more complex parameters such as shadow price factors and discount rates have already been fixed by others. The book includes detailed coverage of uncertainty and risk, and of multicriterion analysis. 
This book originates from my own felt need. While practising as a civil engineer and becoming increasingly involved in feasibility studies, I found I was checking, re-working and editing CBAs originally prepared by economists. When the economist was absent or innumerate, I had to compute the results, and often I had to interpret them for clients or decision-makers who could not understand the terminology. I was always conscious of the partial nature of my understanding of what I was doing. Eventually I went to university and asked the academics to fill the gap. I found that there was a shortage of books, and of teachers, able to explain CBA to people who are fully numerate and understand the details and contexts of planning and project decisions, and who also have some experience of finance, but who lack a formal training in economics. Since taking that postgraduate course I have been able, in some situations, to function as an economist, and often to influence and supervise CBAs done by others.

In 1990 I began to give courses in CBA to graduate engineers and other professionals as part of the in-house training programme of the consulting firm I work for, Mott MacDonald. I learned what sorts of explanation work, and what sorts bring a glazed expression to the audience's eyes. The firm's formal feedback system enabled the participants to comment on my teaching and to contribute to its improvement. I am grateful to Mott MacDonald for permission to take advantage of this experience in writing this book, and for permission to use here some of the material I developed for the course.

I would like to thank many who have helped me to an understanding of CBA and project economics. In particular I am very grateful to the economists and other professionals who have commented on parts of the draft: Colin Bruce, Jim Perry, Clare Rhodes-James, Maureen Sibbons, Brigitte Snell and Michael Yaffey, and especially to the publisher's reviewer, David Potts of the Development and Project Planning Centre, University of Bradford, and to my colleague, mentor and constructive critic Chris Finney. I have not always followed their advice, and indeed this would not be possible because they disagree with each other. The publisher's referees provided useful ideas on content and structure. Finally, I thank the 330 victims of my Mott MacDonald graduate course on project economics held over the last eight years, for their comments and questions, and for their invaluable, and sometimes unintended, feedback on how not to explain things. None of these people, however, should be blamed for the book's shortcomings. 


\section{Preface to the second edition}

The principles of cost-benefit analysis (CBA) have not changed in the years since the 1997 edition was published, but a few useful books and guidelines have been published by others, and these are referred to in this new edition. References to internet sources have also been added.

Some passages have been clarified or extended, and in particular the appendix on multicriterion analysis has been reworked in the light of my experience in the intervening years.

CBA is now more often carried out using spreadsheet or workbook software than it was in 1997, and the guidance has been updated with reference to current commonly used software, including a warning about a particular pitfall in that software.

I acknowledge with gratitude the encouragement of many readers and users of the first edition, especially Chris Finney, Jim Winpenny and Mike Chauhan. They have confirmed that CBA can be understood and used by people who are not formally trained in economics, and that practising economists also appreciate a clear explanation of the subject and its many applications. 
Downloaded by [] on [26/04/23]. Copyright @ ICE Publishing, all rights reserved. 


\section{Introduction}

Cost-benefit analysis (CBA) is a decision-guiding tool that has traditionally been regarded as a branch of economics. This book has been written primarily for non-economists, by a non-economist, because I have found that such people can and should use the tool. To work well in guiding decisions, CBA needs to be understood by the decision-makers and other parties affected by a decision, and this book aims to spread such understanding.

The chapters constitute a complete account of CBA as it affects people who practise it or use its results, but avoiding most of the theoretical details. The basics are given in Chapters 1 to 3. Chapter 4 introduces the special aspects of a number of sectors and project types, using these also to introduce some analytical devices that can apply to many fields. Because the result of a CBA is only useful when a decision-maker understands it and accepts its validity, Chapter 5 gives some guidance on the presentation of a CBA in a report or similar document, or in a personal presentation. Finally, Chapter 6 provides a checklist of steps to be taken and questions to be dealt with, both in the conducting and the reporting of a CBA.

The chapters are designed to be read sequentially, each providing the concepts needed to understand the ones that follow, but they can also be used for reference. Many concepts are explained or illustrated in boxes or figures within the chapters, so as not to interrupt the flow of the main text. Numerical examples are included in the explanatory sections, which the reader using the book as a learning tool can work through if desired, and some chapters end with more extensive questions for which model answers are presented in an appendix. Appendix I contains a worked example of a complete CBA report.

The more specialised theory and the finer distinctions are mostly in the appendices and endnotes, with selective references to the literature. For those using the book as a reference work, the Glossary/Index gives pointers to both chapters and appendices; it brings together cross-references 
to the text and definitions of the main terms and abbreviations. Some of the terms defined in the Glossary/index are identified in the text by being printed in italics.

Notes are collected together at the end of each chapter or appendix. They are mainly references to published literature, and readers should generally ignore them unless they need those references. Many sections and appendices end with pointers to further reading and useful references.

Most of the illustrations and examples are from my own experience, some being composites of more than one actual analysis. Because of this, many of them concern water resources development of some kind, but the concepts and methods are applicable to many fields, and throughout the book the emphasis is on basics and wide application. Because of confidentiality constraints, only those examples and case studies that are already in the public domain are named.

To avoid the use of 'he or she', the reader, analyst or decision-maker is sometimes referred to as female and sometimes as male; any bias in the distribution of usage is unintended. 